\title{
Oral montelukast in acute asthma exacerbations: a randomised, double-blind, placebo-controlled trial
}

\author{
Crichton F Ramsay, ${ }^{1}$ Darcy Pearson, ${ }^{1}$ Sue Mildenhall, ${ }^{1}$ Andrew M Wilson ${ }^{1,2}$
}

${ }^{1}$ Department of Respiratory Medicine, Norfolk \& Norwich University Hospital, Norwich, UK ${ }^{2}$ School of Medicine Health Policy \& Practice, University of East Anglia, Norwich, UK

\section{Correspondence to}

Dr Crichton F Ramsay, Department of Respiratory Medicine, 3rd Floor, East Wing, Norfolk \& Norwich University Hospital, Colney Lane, Norwich NR4 7UY, UK;

crichton.ramsay@nnuh.nhs.uk

Received 11 January 2010 Accepted 28 June 2010 Published Online First 18 October 2010

\begin{abstract}
Background Although leukotriene receptor antagonists have an established role in the management of patients with chronic asthma, their efficacy in an acute asthma exacerbation is not fully known.

Methods 87 adults with acute asthma requiring hospitalisation were randomly assigned to receive either montelukast $10 \mathrm{mg}$ or placebo on admission and every evening thereafter for 4 weeks (when they were reviewed as outpatients). All patients were admitted under the care of a consultant chest physician and received full care for acute asthma according to the British Thoracic Society guidelines. The primary end point was the difference in peak expiratory flow (PEF) between active and placebo treatment the morning following admission.
\end{abstract}

Results Primary end point data were analysed for 73 patients. At study entry, patients who received montelukast $(\mathrm{n}=37$ ) had a mean ( \pm SD) PEF of 227.6 $( \pm 56.9) \mathrm{l} / \mathrm{min}(47.6 \%$ predicted) and those who received placebo $(n=36)$ had a PEF of $240.3( \pm 99.8) \mathrm{l} / \mathrm{min}$ (49.6\% predicted). The morning after admission, patients who received montelukast achieved a PEF of 389.6 $( \pm 109.7)$ l/min $(81.4 \%$ predicted) compared with 332.3 ( \pm 124.9$) \mathrm{l} / \mathrm{min}(69.8 \%$ predicted) for placebo $(p=0.046)$. The mean difference between treatment groups was $57.4 \mathrm{l} / \mathrm{min}(95 \% \mathrm{Cl}$ of 1.15 to $113.6 \mathrm{l} / \mathrm{min}$ or $1.95-21.2 \%$ predicted).

Conclusion In acute asthma exacerbations the additional administration of oral montelukast results in a significantly higher PEF the morning after admission than that acheivable with current standard treatment. Clinical trial number NCT01011452.

\section{INTRODUCTION}

The leukotriene receptor antagonists (LTRAs) have an established role in the management of chronic asthma. ${ }^{1-4}$ LTRAs may also provide benefit, additional to that achieved by current treatment, in acute asthma. ${ }^{5}$ Exacerbations of asthma are associated with increased cysteinyl leukotriene production, as evidenced by raised urinary $\mathrm{LTE}_{4}$ both at the time of admission ${ }^{6}$ and several weeks later. $^{7-10}$ LTRAs have an acute bronchodilator effect additional to the bronchodilatation achieved by inhaled and nebulised $\beta$-agonists, ${ }^{11-14}$ which is seen within 20-60 min of administration of the intravenous drug ${ }^{12} 15$ and within $6 \mathrm{~h}$ of taking the LTRA orally. ${ }^{15} \mathrm{~A}$ small number of studies have shown benefits of LTRAs in acute asthma. ${ }^{15-19}$ The two largest studies using an LTRA in acute asthma are those of Camargo et al (201 patients) and Silverman et al (641 patients). ${ }^{15} 16$ Camargo et al ${ }^{15}$ demonstrated significant improvements in lung function from intravenous montelukast over the first $2 \mathrm{~h}$ while in the emergency room; their patients received $\beta$ agonists but no anticholinergic medication. Silverman et al ${ }^{16}$ primarily assessed the effect of oral zafirlukast on relapses in the 28 day follow-up period following an emergency room attendance. Ferreira et $a l^{18}$ studied 20 adults with acute asthma for their period in the emergency room and showed non-significant trends in favour of montelukast. Harmanci et al ${ }^{17}$ looked at 51 children (aged 2-5years) also in the emergency department and evaluated montelukast's role in avoiding steroids in asthma exacerbations. Cylly et $a l^{19}$ evaluated 70 patients over a $24 \mathrm{~h}$ period comparing montelukast alone with prednisolone alone and montelukast + prednisolone in a singleblinded study where patients also received nebulised $\beta$-agonists (but not nebulised anticholinergics) and showed a non-significant trend in favour of montelukast.

This is the first study looking at patients with an acute asthma exacerbation of a severity that required hospitalisation and who received an LTRA in addition to maximal treatment as set out by the British Thoracic Society. ${ }^{1}$

\section{METHODS}

This was a randomised, double-blind, placebocontrolled, single-centre study. Patients presenting either to the accident and emergency department or the medical admissions unit at Norfolk \& Norwich University Hospital NHS Trust with acute asthma requiring hospitalisation were enrolled. The study was performed without commercial input into or involvement with the design, execution, analysis or reporting. The study had ethical approval from Norfolk Research Ethics Committee and written informed consent was obtained from all participants prior to study entry.

\section{Patients}

The inclusion criteria comprised adults aged between 18 and 50, a primary diagnosis of acute asthma, no other acute pathology and a peak expiratory flow (PEF) at randomisation $\leq 75 \%$ of their known best (within the last 12 months) or, in the absence of this information, of their predicted PEF.

Study patients had to have a lifetime smoking history of $<10$ pack-years. Patients well enough to be discharged after initial treatment were not eligible. Females who were pregnant or breastfeeding or unable to take adequate contraceptive precautions were excluded. Patients already taking an LTRA or phenytoin, phenobarbitone or rifampicin (montelukast affects the levels of these three drugs) were excluded. 


\section{Study design}

Enrolment occurred at the time of the decision to admit or first consultant assessment. Patients were seen by, and admitted under the care of, a consultant chest physician on one of their twice-daily ward rounds. Subjects were randomised to receive either montelukast $10 \mathrm{mg}$ or placebo, in a 1:1 ratio. A study capsule was given at enrolment and then at 22:00 h daily for a period of 4 weeks when they were reviewed in the outpatient clinic. Patients enrolled before 22:00 $\mathrm{h}$ would therefore receive two study capsules on the day of admission. All subjects received oral prednisolone $40 \mathrm{mg}$ at presentation and daily thereafter, and initial treatment with nebulised salbutamol (5 $\mathrm{mg}$ at least every $6 \mathrm{~h}$ ) and nebulised ipratropium $(500 \mu \mathrm{g}$ every $6 \mathrm{~h}$ ). Additional oxygen, intravenous magnesium and/or aminophylline and further nebulised salbutamol were prescribed if indicated. At the 4 week outpatient visit, full pulmonary function tests were performed along with a clinical review, and the study participation ended.

\section{Efficacy measurements}

The protocol-defined primary efficacy measure was the difference between active and placebo treatment in postbronchodilator PEF measured the morning following admission. This end point was chosen as it was felt that in hospitalised patients with asthma the peak flow the morning after admission was the earliest clinically relevant objective asthma measurement that is consistently recorded.

On admission patients had a measurement of PEF made using a new mini-Wright's PEF meter (Clement Clarke International, Harlow, Essex, UK). Patients kept the same PEF meter throughout the study. Inpatients' spirometry was performed between 08:00 $\mathrm{h}$ and 10:00 $\mathrm{h}$ each morning on the same handheld spirometer (Vitalograph) by either SM or one of the consultant chest physicians at Norfolk \& Norwich University Hospital NHS Trust.

\section{Statistical analyses}

It was calculated that 200 patients would need to be enrolled, to allow for withdrawals, in order to have a $80 \%$ chance of detecting a difference of $25 \mathrm{l} / \mathrm{min}$ in PEF at a $5 \%$ level of significance, assuming an $\mathrm{SD}$ of $60 \mathrm{l} / \mathrm{min}$ from previous work in our department. ${ }^{20}$ Data collection and entry was performed by DP and SM, and data analysis was performed by AMW. Data are presented as group mean \pm SD unless otherwise indicated. Statistical testing was performed, as defined in the protocol, on the absolute values of the PEF (not the per cent predicted). Normally distributed data, which included the primary end point data, were analysed using an unpaired t test and categorical data using a $\chi^{2}$ test. Time to discharge data were nonparametric, and are presented as median and interquartile ranges and analysed using Kaplan-Meier survival analysis. Analysis was performed using Microsoft Excel Version 2003 and SPSS 14.0 for windows.

\section{RESULTS}

Recruitment to the study was slow partly due to the moderately stringent entry criteria, and the study was terminated early. Of the 87 enrolled patients 43 were randomised to receive montelukast. Fourteen patients were withdrawn (six from the montelukast limb) from the study, the details of which are in the Consort diagram. Therefore, the data of 73 patients (37 on montelukast) were analysed for the primary end point.

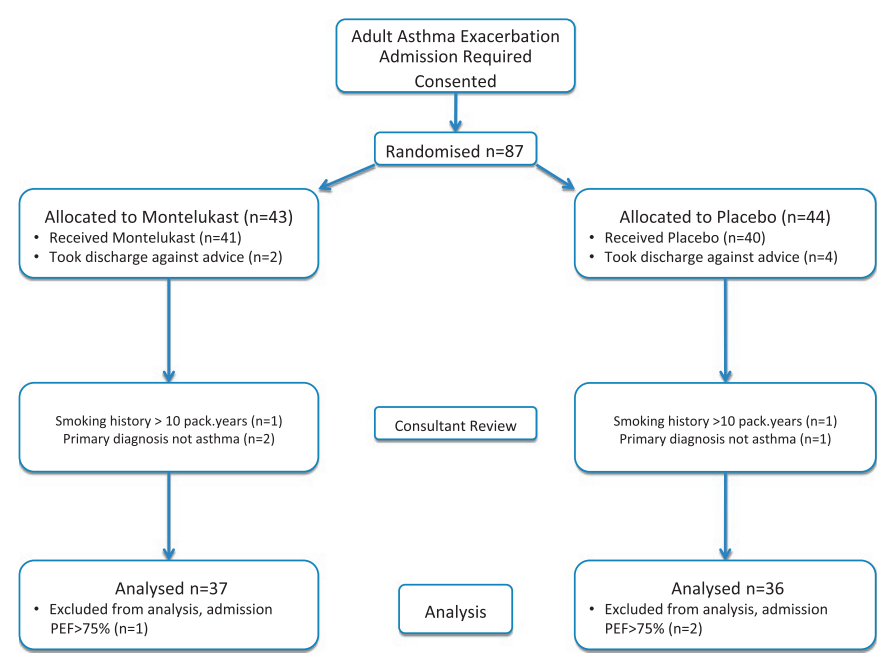

\section{Patient characteristics}

These are summarised in table 1 for the patients on whom the primary end point data were derived. Baseline demographic characteristics were well matched between the treatment groups with no statistically significant differences for any parameters. In particular, the mean PEF at study entry and the known best

Table 1 Study baseline patient characteristics

\begin{tabular}{lll}
\hline & Montelukast & Placebo \\
\hline $\mathrm{n}$ & 37 & 36 \\
Age in years mean (SD) & $28.3(8.5)$ & $30.3(7.8)$ \\
$\begin{array}{l}\text { Male:female, } \mathrm{n} \\
\text { Severity of exacerbation, } \mathrm{n}(\%)\end{array}$ & $15: 22$ & $16: 20$ \\
$\quad$ & & \\
$\quad$ Moderate & $4(11 \%)$ & $9(25 \%)$ \\
$\quad$ Severe & $18(49 \%)$ & $11(31 \%)$ \\
$\quad$ Life threatening & $14(38 \%)$ & $16(44 \%)$ \\
$\quad$ Near fatal & $1(3 \%)$ & 0 \\
Received, n (\%) & & \\
$\quad$ IV Theophylline & $6(16 \%)$ & $3(8 \%)$ \\
$\quad$ IV Magnesium & $1(3 \%)$ & $1(3 \%)$ \\
IV Magnesium and IV aminophylline & $2(5 \%)$ & 0 \\
$\quad$ Total & $9(24 \%)$ & $4(11 \%)$ \\
Asthma history & & \\
$\quad$ Years, mean (SD), since diagnosis & $15.1(9.7)$ & $18.5(9.0)$ \\
Previous admission to intensive care & $8(21 \%)$ & $2(5 \%)$ \\
Exacerbations in last year, $\mathrm{n}(\%)$ & & $26(72 \%)$ \\
$\quad 0$ & $22(59 \%)$ & $4(11 \%)$ \\
1 & $8(22 \%)$ & $4(11 \%)$ \\
$2-3$ & $5(14 \%)$ & $2(6 \%)$ \\
$>3$ & $2(5 \%)$ &
\end{tabular}

Regular treatment at presentation

Inhaled corticosteroids (BDP/24 h or equivalent), $\mathrm{n}(\%)$

\begin{tabular}{lll} 
Prescribed but not being taking & $14(38 \%)$ & $10(28 \%)$ \\
Not prescribed & $4(11 \%)$ & $6(17 \%)$ \\
Patient unable to state dose & $5(14 \%)$ & $3(8 \%)$ \\
$0-400 \mu \mathrm{g}$ & $5(14 \%)$ & $6(17 \%)$ \\
$400-800 \mu \mathrm{g}$ & $1(3 \%)$ & $2(6 \%)$ \\
$>800 \mu \mathrm{g}$ & $8(21 \%)$ & $9(25 \%)$ \\
Long-acting $\beta$-agonists & $14(36 \%)$ & $9(23 \%)$ \\
Other asthma drugs (but not LTRAs) & $4(11 \%)$ & $3(8 \%)$ \\
\hline
\end{tabular}

BDP, beclomethasone dipropionate; IV, intravenous; LTRA, leukotriene receptor antagonist. 
or predicted PEF were almost identical in each group. With the exception of two patients, in whom the admission was their first diagnosis of asthma, all patients were taking a short-acting $\beta$-agonist (SABA) at presentation. Only 39 (53\%) patients were being prescribed and were concordant with regular inhaled corticosteroids (ICS) prior to admission. A total of $85 \%$ of subjects had a smoking history of less than five pack-years and $40 \%$ of subjects were never smokers. In 60 patients (>80\%) the severity of the attack was severe, life-threatening or near fatal as classified in the British Thoracic Society (BTS) guidelines, ${ }^{1}$ although in only 13 (18\%) was either intravenous magnesium and/or aminophylline prescribed.

\section{Primary outcome measures}

Patients who received montelukast had a significantly $(p=0.046)$ higher PEF than those who received placebo the morning after admission. The mean difference between treatment groups was $57.4 \mathrm{l} / \mathrm{min}$ (95\% CI of 1.15 to $113.6 \mathrm{l} / \mathrm{min}$ ). The data and graphics for the PEF profile during the study are presented in figure 1 and table 2 .

\section{Secondary outcome measures}

By the time of discharge the PEF difference between the treatment groups had fallen to $41.6 \mathrm{l} / \mathrm{min}$ (95\% CI -2.5 to $85.6 \mathrm{l} /$ min) which was non-significant $(p=0.064)$, and at the 4 week clinic visit the PEFs were essentially the same. The data for all the other secondary end points are presented in table 3 . There were no statistically significant differences for any of secondary end points. None of the study participants required intubation and there were no deaths or any serious adverse events reported during the study.

\section{DISCUSSION}

The magnitude of benefit from montelukast in this study is comparable with previous publications on the use of LTRAs in acute $^{15-18}$ and chronic ${ }^{3}{ }^{12-14}$ asthma and compares favourably with other drugs used in addition to steroids and nebulised $\beta$-agonists in acute asthma. ${ }^{21-30}$

Acute asthma studies differ in how they present and analyse PEF data, some comparing PEF data by numerical value (as we have done) some comparing the PEF as percentage best/ predicted and others comparing relative changes in PEF. It could be argued that comparing the percentage best/predicted is more clinically relevant and in this study the difference between montelukast (81.4\%) and placebo (69.8\%) the morning after admission was significant at $\mathrm{p}=0.019$.

Camargo showed a $14.8 \%$ improvement at $2 \mathrm{~h}$ from baseline forced expiratory volume in $1 \mathrm{~s}\left(\mathrm{FEV}_{1}\right)$ for intravenous montelukast compared with $3.6 \%$ for placebo $(p=0.007)$ in patients

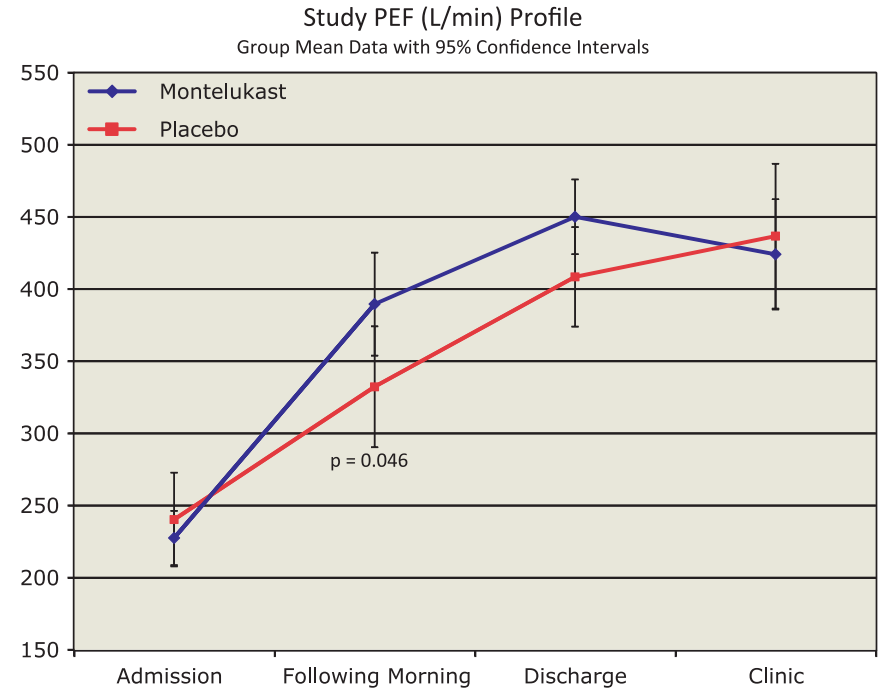

Figure 1 Study peak expiratory flow (PEF) profile.

with acute asthma with a presentation $\mathrm{FEV}_{1}$ of just under $50 \%$ predicted. ${ }^{15}$ While Silverman et al were primarily assessing outpatient relapses, prior to their discharge from the emergency department, there was a small benefit in $\mathrm{FEV}_{1}$ (2.12 litres vs 2.03 litres) in favour of oral Zafirlukast $(p=0.04)$ at $3.5 \mathrm{~h}^{16}$

In subjects with stable asthma, not given any other acute treatments, with a baseline $\mathrm{FEV}_{1}$ of $63 \%$, oral montelukast produced a $15.72 \%$ improvement in $\mathrm{FEV}_{1}$, compared with $7.75 \%$ for placebo and $20.7 \%$ for the intravenous form (area under the curve of percentage change from baseline). ${ }^{12}$ Similarly Gaddy et al showed that intravenous LTRA could produce a $22 \%$ improvement in $\mathrm{FEV}_{1}$ from baseline in those with stable asthma with a baseline $\mathrm{FEV}_{1}$ of $50-80 \%$ predicted. ${ }^{13}$

Improvements in PEF expressed as a percentage of the baseline PEF value will invariably be larger than if expressed as a percentage of the predicted PEF. In this study, the montelukast group had a mean PEF improvement of $162.1 \mathrm{l} / \mathrm{min}$ compared with the placebo group's $92.0 \mathrm{l} / \mathrm{min}$ which is a $33.8 \%$ and $20.2 \%$ improvement, respectively, of their predicted/best PEF. However, expressing the change as a percentage from baseline would show a $72 \%$ improvement for the montelukast group and $38 \%$ for placebo.

The benefit from montelukast of $57.4 \mathrm{l} / \mathrm{min}$ the morning following admission had fallen to a non-significant $41.6 \mathrm{l} / \mathrm{min}$ by the time of discharge. However, one of the criteria by which patients are judged to be fit for discharge is a PEF of $\geq 80 \%$ of their best/predicted. Fulfilling this PEF criterion reduces the likelihood of there being a difference between treatment groups

Table 2 Study peak expiratory flow (PEF) data profile group

\begin{tabular}{|c|c|c|c|c|}
\hline & Admission & Following morning* & Discharge & 4 weeks \\
\hline \multicolumn{5}{|c|}{ Actual value of PEF, $1 / \mathrm{min}$} \\
\hline Montelukast & $227.5( \pm 56.9)$ & $389.6( \pm 109.7)^{*}$ & $450.1( \pm 80.6)$ & $424.1( \pm 103.6)$ \\
\hline Placebo & $240.3( \pm 99.8)$ & $332.3( \pm 124.9)^{*}$ & $408.5( \pm 105.8)$ & $436.7( \pm 125.5)$ \\
\hline Difference $95 \% \mathrm{Cl}$ & -50.9 to 25.5 & 1.15 to $113.6^{*}$ & -2.5 to 85.6 & -77.6 to 52.3 \\
\hline $\mathrm{p}$ Value & 0.508 & $0.046^{*}$ & 0.064 & 0.698 \\
\hline \multicolumn{5}{|c|}{ PEF expressed as a percentage of patients best/predicted } \\
\hline Montelukast & $47.7( \pm 11.6)$ & $81.4( \pm 19.5)$ & $94.1( \pm 14.5)$ & $89.2( \pm 19.1)$ \\
\hline Placebo & $49.6( \pm 15.3)$ & $69.8( \pm 20.7)$ & $86.1( \pm 21.2)$ & $91.5( \pm 25.4)$ \\
\hline Difference $95 \% \mathrm{Cl}$ & -8.3 to 4.4 & 2.0 to 21.2 & -0.6 to 16.5 & -15.1 to 10.4 \\
\hline $\mathrm{p}$ Value & 0.543 & 0.019 & 0.067 & 0.715 \\
\hline
\end{tabular}


Table 3 Secondary end points

\begin{tabular}{lccc}
\hline & Montelukast & Placebo & p Value \\
\hline Lung function at 4 weeks & & & \\
FEV $_{1}$ (litres) & $3.03(0.74)$ & $3.20(0.86)$ & 0.464 \\
FEV $_{1}$ (\% predicted) & $83.52(26.6)$ & $89.27(17.0)$ & 0.363 \\
RV (litres) & $1.92(0.52)$ & $2.10(0.75)$ & 0.884 \\
RV/TLC, \% & $30.7(7.2)$ & $32.0(7.0)$ & 0.540 \\
& & & \\
& Median (IOR) & & \\
No. of days as inpatient & $3(2-4)$ & $3(1-3.25)$ & 0.509 \\
\hline
\end{tabular}

$\mathrm{FEV}_{1}$, forced expiratory volume in $1 \mathrm{~s}$; RV, residual volume; TLC, total lung capacity.

at discharge, although it might be anticipated that the time to achieve the $80 \%$ PEF threshold would be shorter in the montelukast group. There was no difference in time to discharge, but a study would require far more patients than we had in order to be able to detect such a difference in these data (which are invariably non-parametric).

Lung function at the outpatient visit also showed no differences between montelukast and placebo. In both treatment limbs patients had on average completed a 9-day course of oral prednisolone at $40 \mathrm{mg} /$ day $<3$ weeks earlier and were receiving high doses of ICS daily. There was no demonstrable benefit of an LTRA in what were now well-controlled patients with asthma, following a course of prednisolone, with near normal lung function.

The main weakness of this study is its size (with only 73 patient's data available for the primary end point it had $80 \%$ power to detect a $40 \mathrm{l} / \mathrm{min}$ difference) and, although the baseline characteristics of both groups were well matched, the numbers of patients who received intravenous magnesium and/or aminophylline differed. In total $9(24 \%)$ patients on montelukast received aminophylline and/or magnesium compared with only $4(11 \%)$ on placebo.

We performed two posthoc subgroup analyses and present the PEF data the morning after admission by treatment subgroups.

In the first analysis we looked at the prescription of additional intravenous aminophylline/magnesium $(n=13)$.

In patients who received intravenous aminophylline/magnesium, the PEF results were: montelukast $331.8 \mathrm{l} / \mathrm{min}$ ( \pm 88.6 ), placebo $184.0 \mathrm{l} / \mathrm{min}( \pm 92.1), 95 \% \mathrm{CI}$ for difference between treatment groups +10.8 to $+284.7 \mathrm{l} / \mathrm{min}$. For patients who did not receive either intravenous aminophylline/magnesium the results were: montelukast $406.2 \mathrm{l} / \mathrm{min}$ ( \pm 110.8 ), placebo $352.0 \mathrm{l} /$ $\min ( \pm 115.9), 95 \%$ CI for difference between treatment groups -5.5 to $+113.8 \mathrm{l} / \mathrm{min}$.

We also performed a posthoc analysis by usage of ICS prior to admission ( $\mathrm{n}=39$ ).

In patients on ICS prior to admission the PEF results were: montelukast $375.5 \mathrm{l} / \mathrm{min}$ ( \pm 101.5$)$, placebo $313.1 \mathrm{l} / \mathrm{min}$ $( \pm 115.0), 95 \%$ CI for difference between treatment groups -10.2 to $+135.1 \mathrm{l} / \mathrm{min}$. For patients not on ICS the results were: montelukast $405.41 / \mathrm{min}$ ( \pm 119.3$)$, placebo $353.91 / \mathrm{min}$ ( \pm 135.5$), 95 \%$ CI for difference between treatment groups -39.5 to $+142.5 \mathrm{l} / \mathrm{min}$. While it is of interest to split the data into these subgroups this was not the per-protocol analysis and the smaller numbers in the subgroups preclude any reliable inferences to be drawn.

In conclusion, in adults presenting with an acute asthma exacerbation requiring hospitalisation, the addition of oral montelukast led to a significantly greater PEF by the morning after admission than that which was achievable with maximal current standard treatment alone. Given the good safety profile of oral montelukast and the ease of administration it would seem reasonable to consider its routine use in asthma exacerbations.

Acknowledgements We would like to acknowledge the help in completing this study provided by Consultant colleagues in the Departments of Respiratory Medicine (Drs P F Grunstein, B D W Harrison, M C Pasteur, O P Twentyman and S W Watkin), Medical Admissions Unit (Drs P F Jenkins and J Southgate) and Accident \& Emergency (Drs T Daynes, B Finlayson, M Lambert and K Walters) for their support in entering patients into this study and facilitating the data collection; the large numbers of junior doctors on these units between 2001 and 2004 who contributed to entering patients, particularly Drs D Ellis, L Howard and 0 Barakat; and nursing support from M Dolding, D Stidson and G Rushbrook.

Funding We are grateful for funding of $£ 15000$ from Merck Sharp \& Dohme (manufacturers of Montelukast) and $£ 5000$ from the Norfolk Association of Asthma Nurses towards the costs of this study.

Competing interests CFR has received educational grants towards attending international conferences and speakers fees from Merck Sharp \& Dohme and has previously participated in their advisory boards. He has also previously received educational grants towards attending international conferences and speakers fees from GSK. Whilst a research registrar, part of the funding for his posts came indirectly from SmithKline Beecham and MSD. AMW is currently the principal investigator of a clinical study funded by Merck. He is also currently undertaking studies for Bayer, Schering Plough, Pharmxis and Boehringer Ingelheim. He has given talks for GSK,

Merck and Astra-Zenica in the last 3 years. He undertook some consultancy work for GSK in April 2007. DP and SM have no competing interests.

Ethics approval This study was conducted with the approval of the Norfolk Research Ethics Committee.

Provenance and peer review Not commissioned; externally peer reviewed.

\section{REFERENCES}

1. British guideline on the management of asthma. Thorax 2003;58(Suppl 1):i1-94. Revised 2008 and 2009

2. Global Initiative for Asthma (GINA). Global Strategy for Asthma Management and Prevention. Updated 2009. http://www.ginasthma.com.

3. Kemp JP, Minkwitz MC, Bonuccelli CM, et al. Therapeutic effect of zafirlukast as monotherapy in steroid-naive patients with severe persistent asthma. Chest 1999;115:336-42.

4. Reiss TF, Chervinsky P, Dockhorn RJ, et al. Montelukast, a once-daily leukotriene receptor antagonist, in the treatment of chronic asthma: a multicenter, randomized double-blind trial. Montelukast Clinical Research Study Group. Arch Intern Med 1998; 158:1213-20

5. Kuitert LM, Barnes NC. Leukotriene receptor antagonists: useful in acute asthma? Thorax 2000;55:255-6.

6. Drazen JM, O'Brien J, Sparrow D, et al. Recovery of leukotriene E4 from the urine of patients with airway obstruction. Am Rev Respir Dis 1992;146:104-8.

7. Green SA, Malice MP, Tanaka W, et al. Increase in urinary leukotriene LTE4 levels in acute asthma: correlation with airflow limitation. Thorax 2004;59:100-4.

8. Taylor GW, Taylor I, Black P, et al. Urinary leukotriene E4 after antigen challenge and in acute asthma and allergic rhinitis. Lancet 1989;1:584-8.

9. Schwartzberg SB, Shelov SP, Van Praag D. Blood leukotriene levels during the acute asthma attack in children. Prostaglandins Leukot Med 1987;26:143-55.

10. Sampson AP, Castling DP, Green $\mathrm{CP}$, et al. Persistent increase in plasma and urinary leukotrienes after acute asthma. Arch Dis Child 1995;73:221-5.

11. Lammers JW, Van Daele P, Van den Elshout FM, et al. Bronchodilator properties of an inhaled leukotriene D4 antagonist (verlukast-MK-0679) in asthmatic patients. Pulm Pharmacol 1992;5:121-5.

12. Dockhorn RJ, Baumgartner RA, Leff JA, et al. Comparison of the effects of intravenous and oral montelukast on airway function: a double blind, placebo controlled, three period, crossover study in asthmatic patients. Thorax 2000;55:260-5.

13. Gaddy JN, Margolskee DJ, Bush RK, et al. Bronchodilation with a potent and selective leukotriene D4 (LTD4) receptor antagonist (MK-571) in patients with asthma. Am Rev Respir Dis 1992;146:358-63.

14. Hui KP, Barnes NC. Lung function improvement in asthma with a cysteinylleukotriene receptor antagonist. Lancet 1991;337:1062-3.

15. Camargo CA Jr, Smithline HA, Malice MP, et al. A randomized controlled trial of intravenous montelukast in acute asthma. Am J Respir Crit Care Med 2003;167:528-33.

16. Silverman RA, Nowak RM, Korenblat PE, et al. Zafirlukast treatment for acute asthma: evaluation in a randomized, double-blind, multicenter trial. Chest 2004; 126:1480-9.

17. Harmanci K, Bakirtas A, Turktas I, et al. Oral montelukast treatment of preschoolaged children with acute asthma. Ann Allergy Asthma Immunol 2006;96:731-5.

18. Ferreira MB, Santos AS, Pregal AL, et al. Leukotriene receptor antagonists (Montelukast) in the treatment of asthma crisis: preliminary results of a double-blind placebo controlled randomized study. Allerg Immunol (Paris) 2001;33:315-18. 
19. Cylly A, Kara A, Ozdemir T, et al. Effects of oral montelukast on airway function in acute asthma. Respir Med 2003;97:533-6.

20. Innes NJ, Stocking JA, Daynes TJ, et al. Randomised pragmatic comparison of UK and US treatment of acute asthma presenting to hospital. Thorax 2002;57:1040-4.

21. Bradshaw TA, Matusiewicz SP, Crompton GK, et al. Intravenous magnesium sulphate provides no additive benefit to standard management in acute asthma. Respir Med 2008;102:143-9.

22. Mohammed S, Goodacre S. Intravenous and nebulised magnesium sulphate for acute asthma: systematic review and meta-analysis. Emerg Med J 2007:24:823-30.

23. Porter RS, Nester BA, Braitman LE, et al. Intravenous magnesium is ineffective in adult asthma, a randomized trial. Eur J Emerg Med 2001:8:9-15.

24. Rodrigo G, Rodrigo C, Burschtin 0. A meta-analysis of the effects of ipratropium bromide in adults with acute asthma. Am J Med 1999:107:363-70.
25. Rodrigo GJ, Rodrigo C. IV magnesium in the treatment of acute severe asthma? Chest 2003; 123:1314-15; author reply 5-6.

26. Rowe BH, Camargo CA Jr. The role of magnesium sulfate in the acute and chronic management of asthma. Curr Opin Pulm Med 2008:14:70-6.

27. D'Avila RS, Piva JP, Marostica PJ, et al. Early administration of two intravenous bolus of aminophylline added to the standard treatment of children with acute asthma. Respir Med 2008;102:156-61.

28. Silverman RA, Osborn H, Runge J, et al. IV magnesium sulfate in the treatment of acute severe asthma: a multicenter randomized controlled trial. Chest 2002:122:489-97.

29. Stoodley RG, Aaron SD, Dales RE. The role of ipratropium bromide in the emergency management of acute asthma exacerbation: a metaanalysis of randomized clinical trials. Ann Emerg Med 1999;34:8-18.

30. Zainudin BM, Ismail O, Yusoff K. Effect of adding aminophylline infusion to nebulised salbutamol in severe acute asthma. Thorax 1994:49:267-9. 